OLGU YAZISI / CASE REPORT

\title{
Triküspid Kapağın Hemanjiomu
}

Hemangioma of the Tricuspid Valve

\author{
Adem Illkay DiKEN', Adnan YALÇINKAYA', Onur HANEDAN², Ahmet IRDEM², Şeref KÜÇÜKER² \\ 'Çorum Devlet Hastanesi, Kalp Damar Cerrahisi Kliniği, Çorum \\ ${ }^{2}$ Ankara Türkiye Yüksek Ihtisas Eğitim ve Araştırma Hastanesi, Kalp Damar Cerrahisi Kliniği, Ankara

\begin{abstract}
ÖZET
Oldukça nadir görülen lezyonlar olan kalp kapak tümörleri kalbin primer neoplastik oluşumlarının \%10 kadarını oluşturmaktadırlar. Literatürde triküspid kapakta yer alan hemanjioma oldukça nadir rastlanmaktadır. Olgumuz olan 17 yaşında erkek hasta perimembranöz ventriküler septal defekt nedeniyle opere edilirken triküspid kapağın anterior leafletinde $7 \times 5 \mathrm{~mm}$ boyutlarında bir lezyon saptanarak eksize edilmiş ve patolojisi benign vasküler proliferasyon; hemanjiom olarak rapor edilmiştir. Bu olguyu literatürde nadir rastlanması ve özellikle konjenital operasyonlarda eşlik edebilecek patolojiler açısından inspeksiyonun önemini vurgulamak amacıyla sunmaktayız.
\end{abstract}

Anahtar Kelimeler: Triküspit kapak, hemanjiyom, neoplazi

\section{ABSTRACT}

Cardiac valve tumors are rare, accounting for less than $10 \%$ of all primary cardiac tumors. Hemangiomas of the tricuspid valve are rarely documented in the literature. A $7 \times 5 \mathrm{~mm}$ lesion was determined and resected during the operation of a 17-year-old male who underwent surgery for perimembranous ventricular septal defect and documented as benign vascular proliferation; hemangioma in the pathology report. We report this case because of it's rarity and to demostrate the importance of inspection for the lesions which can especially accompany to congenital cardiac diseases.

Keywords: Tricuspid valve, hemangioma, neoplasia 


\section{Giriş̧}

Gelişen tanı teknikleriyle çoğu konjenital kalp hastalığına erken müdahale edilebilmektedir. Kompleks kalp anomalilerinde ise ön plandaki patoloji aydınlatılmaya çalışılırken eşlik eden insidental minör patolojiler gözden kaçabilmektedir. Özellikle neoplazilerin oldukça nadir gözlendiği bir lokalizasyon olan kalpte, daha da nadir bir patoloji olan kalp kapağı tümörlerinin preoperatif dönemde uygulanan tanı yöntemleriyle saptanması güç olabilmektedir. Bu olgu sunumunda ventriküler septal defekt nedeniyle opere edilen bir hastada intraoperatif olarak tespit edilen ve triküspit kapakta yetmezliğe neden olan hemanjiom takdim edilmektedir.

\section{OLGU SUNUMU}

On yedi yaşındaki erkek hasta yaklaşık on yıldır devam eden, eforla artan nefes darlığı ve bir kez gözlenen senkop şikayetiyle kliniğimize başvurdu. Senkopa yönelik yapılan incelemede nörolojik bir bozukuluk saptanmadı. Fizik muayenesinde oskültasyonla duyulan üçüncü derecede pansistolik üfürüm dışında anormal bulgu saptanmadı. Elektrokardiyografisi normal sinüs ritmindeydi. Telekardiyografisinde kardiyomegali saptanmadı. Yapılan transtorasik ekokardiyografide perimembranöz bölgede yaklaşık $0,6 \mathrm{~cm}$ boyutunda defekt izlendi. Defekt üzerinde soldan sağa geçiş olmakta ve $84 \mathrm{mmHg}$ gradiyent bulunmaktaydı. Pulmoner akım ile sistemik akım oranı (Qp / Qs) 1.9 saptanan hastaya operasyon kararı verildi. Hastada 2 . derecede triküspit yetmezliği bulunmaktaydı. Median sternotomi yaklaşımıyla aortobikaval kanulasyon uygulandı. Standart teknikle kardiyopulmoner baypasa girildi. Sağ atriotomi yapıldı. Triküspit kapağın septal leafleti retrakte edilerek perimembranöz ventriküler septal defekt ekspoze edildi. Tek tek pledgetli sutürlerle double velor yama kullanılarak kapatıldı. Bu sırada triküspit kapağın anterior leafletindeki 7 x 5 mm boyutundaki pürüzlü yüzeyli, üzerine basınca solan ve küçülen lezyon saptandı (Şekil 1). Lezyon kapakta retraksiyona neden olmakta ve koaptasyonu engellemekteydi. Lezyon kuadrangüler rezeksiyonla eksize edildi. Leaflette oluşan defekt 6-0 poliproplien dikişlerle kapatıldı. İntra-

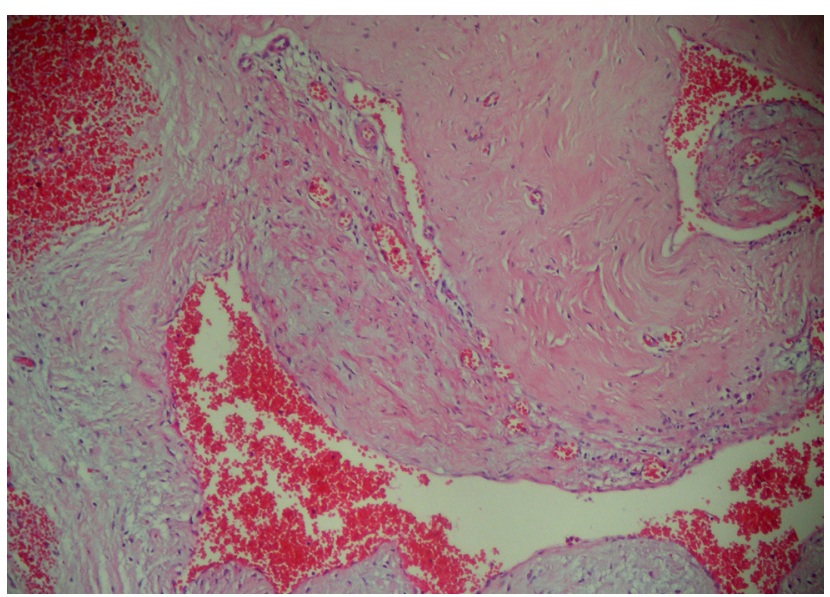

Şekil 1: Bu histolojik örnekte hemanjiyom tanısı için gerekli kriterlerden olan geniş, düzensiz, içerisi kan hücreleriyle dolu endotelle döşeli vasküler yapılar gözlenmektedir.

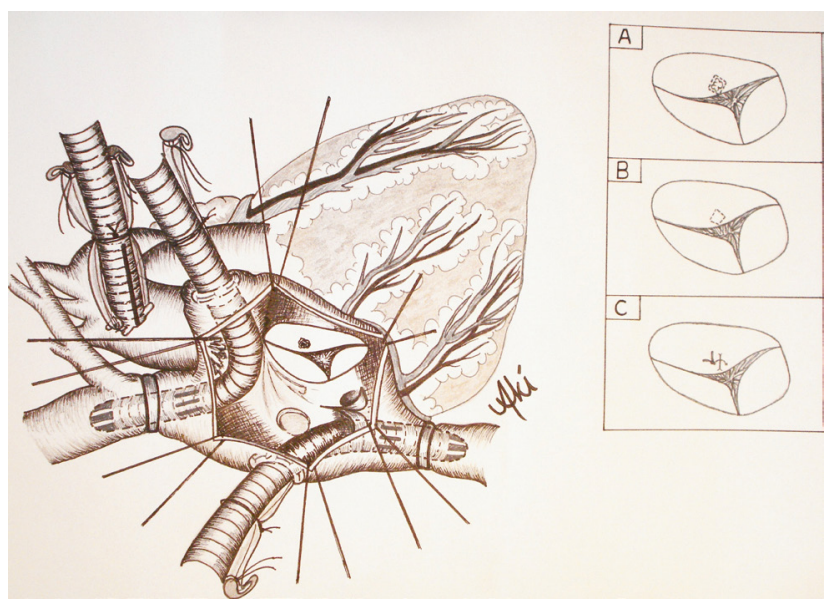

Şekil 2: Cerrah pozisyonundan triküspid kapağın anterior leafletindeki hemanjiyom görülmektedir.

operatif salin ile muayenede minimal triküspit yetmezliği olduğu görüldü. Mevcut olan patent foramen ovale primer sutürle kapatıldıktan sonra problemsiz bir şekilde operasyona son verildi. Spesimenin patolojik incelemesinde yer yer mikzoid dejenerasyon gösteren fibröz stroma içerisinde farklı büyüklüklerde, bir kısmı kapiller, bir kısmı büyük endotelle döşeli, içlerinde eritrosit bulunan damar yapıları gözlendi (Şekil 2). Lezyon benign vasküler proliferasyon; hemanjiyom olarak rapor edildi. Postoperatif seyri problemsiz tamamlanan hasta ameliyat sonrası beşinci günde şifa ile taburcu edildi. Dört ay sonraki kontrolünde transtorasik ekokardiyografide ventriküler septumun intakt olduğu ve 1 . derecede triküspit yetmezliğinin devam ettiği gözlendi. Eforla olan dispnesinin büyük oranda gerilediği ayrıca yeni bir senkop atağının olmadığı öğrenildi. 


\section{TARTIŞMA}

Kalpte neoplastik oluşumlara oldukça nadir rastlanmaktadır. Primer kardiyak tümörlerin $\% 72$ 'si benign tümörlerdir ve bunların \% 5 ile \% 10 kadarını hemanjiyomlar oluşturmaktadır (1). Kardiyak kapak tümörleri primer kardiyak tümörlerin \% 10 kadarıdır (2). Kalp kapakları anulüse komşu 1/3'lük kısım haricinde özellikle avasküler alanlardır. Literatürde triküspid kapakta benign vasküler bir oluşum olan hemanjiyom oldukça nadir bildirilmiştir ve çoğunun vaka takdimi şeklinde olduğu göze çarpmaktadır. Sunmakta olduğumuz vakada triküspid kapağın anterior leafletinde yer alan ve preoperatif tetkiklerde fark edilmemiş bir hemanjiyom intraoperatif inspeksiyon sırasında ko-insidental olarak tespit edilip rezeke edilmiştir. Bu durum kardiyak cerrahide dikkatli bir inspeksiyonun önemini vurgulamaktadır. Özellikle konjenital kalp cerrahisinde bu durum daha çok önem kazanmaktadır.

Kardiyak hemanjiyomlar genellikle asemptomatik olmakla beraber nadir de olsa dispne, aritmiler, çıkım yolu obstruksiyonları, koroner yetmezlik ve perikardiyal efüzyona neden olabilmektedir $(3,4)$. Hemanjiyomların tanısı preoperatif yapılan transtorasik veya transözefagial ekokardiyografi ile konulabilmekte fakat küçük lezyonların olması durumunda tespit edilememektedir. Bununla beraber bizim vakamızda olduğu gibi eşlik eden anomalilerin varlığında gözden kaçabilmektedir. Kontrastlı bilgisayarlı tomografi veya manyetik rezonans görüntüleme hemanjiyomların tetkikinde oldukça duyarlı olan tekniklerdendir (5). Koroner anjiografide tümoral boyanma görülebilir (4). Bu tümörlerin doğal seyri oldukça değişkendir. Tamamen uykuda ve klinik olarak sessiz seyredebilir veya bir süre sonra prolifere olabilirler (6). Genel inanış tüm kardiyak kapak tümörlerinin rezeke edilmesi yönündedir $(2,7)$. Cerrahi rezeksiyon sonrası uzun dönem prognozu oldukça iyidir (4).

Özellikle kompleks konjenital operasyonlarda ve patolojilerde eşlik edebilecek kapak tümörleri gibi akla zor gelebilecek oluşumlar kolaylıkla hem preoperatif hem de postoperatif dönemde gözden kaçabilmektedir. Sonrasında redo operasyonlara neden olabilecek bu gibi durumlardan kaçınmak için intraoperatif dikkatli eksplorasyonun önemi kaçınılmazdır.

\section{KAYNAKLAR}

1. Burke A, Virmani R. Tumors of the heart and great vessels. In: Rosai J, Sobin LH, editors. Atlas of tumor pathology, 3rd series fascicle 16. Washington (DC): Armed Forces Institute of Pathology, 1996: 80- 6.

2. Edwards FH, Hale D, Cohen A, et al. Primary cardiac valve tumors. Ann Thorac Surg 1991;52(5):112731.

3. Burke A, Johns JP, Virmani R. Hemangiomas of the heart. A clinicopathologic study of ten cases Am J Cardiovasc Pathol 1991;13(4):283-90.

4. Brizard C, Latremouille C, Jebara VA, et al. Cardiac hemangiomas. Ann Thorac Surg 1993;56(2):390- 4.

5. Kemp JL, Kessler RM, Raizada V, et al. Case report. MR and CT appearance of cardiac hemangioma. J Comput Assist Tomogr 1996;20(3):482-3.

6. Kann BR, Kim WJ, Cilley JH, et al. Hemangioma of the right ventricular outflow tract. Ann Thorac Surg 2000;70(3):975-7.

7. Sun JP, Asher CR, Yang XS, et al. Clinical and echocardiographic characteristics of papillary fibroelastomas: a retrospective and prospective study in 162 patients. Circulation 2001;103(22):2687-93. 